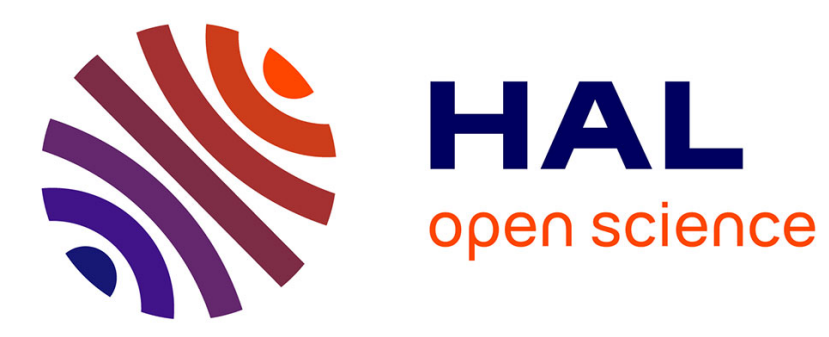

\title{
Nutrition in social insects
}

Stéphane Kraus, Tamara Gomez-Moracho, Mathieu Lihoreau

\section{To cite this version:}

Stéphane Kraus, Tamara Gomez-Moracho, Mathieu Lihoreau. Nutrition in social insects. Christopher K. Starr. Encyclopedia of Social Insects, Springer, pp.1 - 5, 2019, 978-3-319-90306-4. 10.1007/978-3319-90306-4_88-2 . hal-02325323

\section{HAL Id: hal-02325323 \\ https://hal.science/hal-02325323}

Submitted on 24 Dec 2021

HAL is a multi-disciplinary open access archive for the deposit and dissemination of scientific research documents, whether they are published or not. The documents may come from teaching and research institutions in France or abroad, or from public or private research centers.
L'archive ouverte pluridisciplinaire HAL, est destinée au dépôt et à la diffusion de documents scientifiques de niveau recherche, publiés ou non, émanant des établissements d'enseignement et de recherche français ou étrangers, des laboratoires publics ou privés. 


\title{
Nutrition in Social Insects
}

\author{
Stéphane Kraus, Tamara Gómez-Moracho and Mathieu Lihoreau \\ Research Center on Animal Cognition (CRCA), Center for Integrative Biology (CBI); CNRS, University \\ Paul Sabatier, Toulouse, France
}

\section{Synonyms}

Feeding; Food

Nutrition concerns physiological and behavioral processes involved in the acquisition of nutrients and other chemicals required for energy, growth, tissue maintenance, and reproduction. While some components are synthetized by the insects themselves, many are ingested with the food, which for social insects can be as diverse as plant leaves, flower pollen and nectar, honey- dew, dead arthropods, or even wood. The chal- lenge for insects is to ingest these foods in appropriate amounts and balance to avoid harmful excesses or deficits of nutrients or toxins. For an individual, nutritional regulation is achieved through a complex interplay between foraging decisions (e.g., based on learning and memory), preingestive processing of food (e.g., enzymatic degradation in the mouthparts), and postingestive assimilation (e.g., absorption and differential utilization of nutrients). For a colony, food collec- tion, processing, assimilation, and excretion are decentralized processes achieved collectively by different individuals with divergent nutritional needs (Fig. 1).

\section{Required Nutrients}

There is considerable overall qualitative sameness in the nutrient requirements by animals across the animal kingdom, including in social insects, although the forms in which they are utilized show extreme variation [3]. Among the main macronutrients required by insects, carbohydrates - which include simple sugars, starch, and other polysaccharides - are the usual respiratory fuel that can be converted to lipids and provide the carbon skeleton for the synthesis of various amino acids. All insects can synthetize glucose sugar by gluconeogenesis, utilizing metabolic intermedi- ates derived from lipids or amino acids. Fatty acids, phospholipids, and sterols are important components of the cellular membranes. Phospholipids and many fatty acids can be synthetized from carbohydrates. However, some polyunsatu- rated fatty acids and all sterols must be acquired from the food. Amino acids are required for the synthesis of proteins, which are used for structural purposes, as enzymes, for transport, storage, and as receptors of other molecules. Most insects obtain amino acids from compounds of dietary protein, except for nine to ten essential amino acids that cannot be synthetized. Among the main micronutrients, vitamins are organic com- pounds required in trace amounts for sustained growth. Minerals include various metal ions that are required as coenzymes and in meta- lloenzymes, but also sodium, potassium, phos- phate, and chloride for cellular ionic balance. 


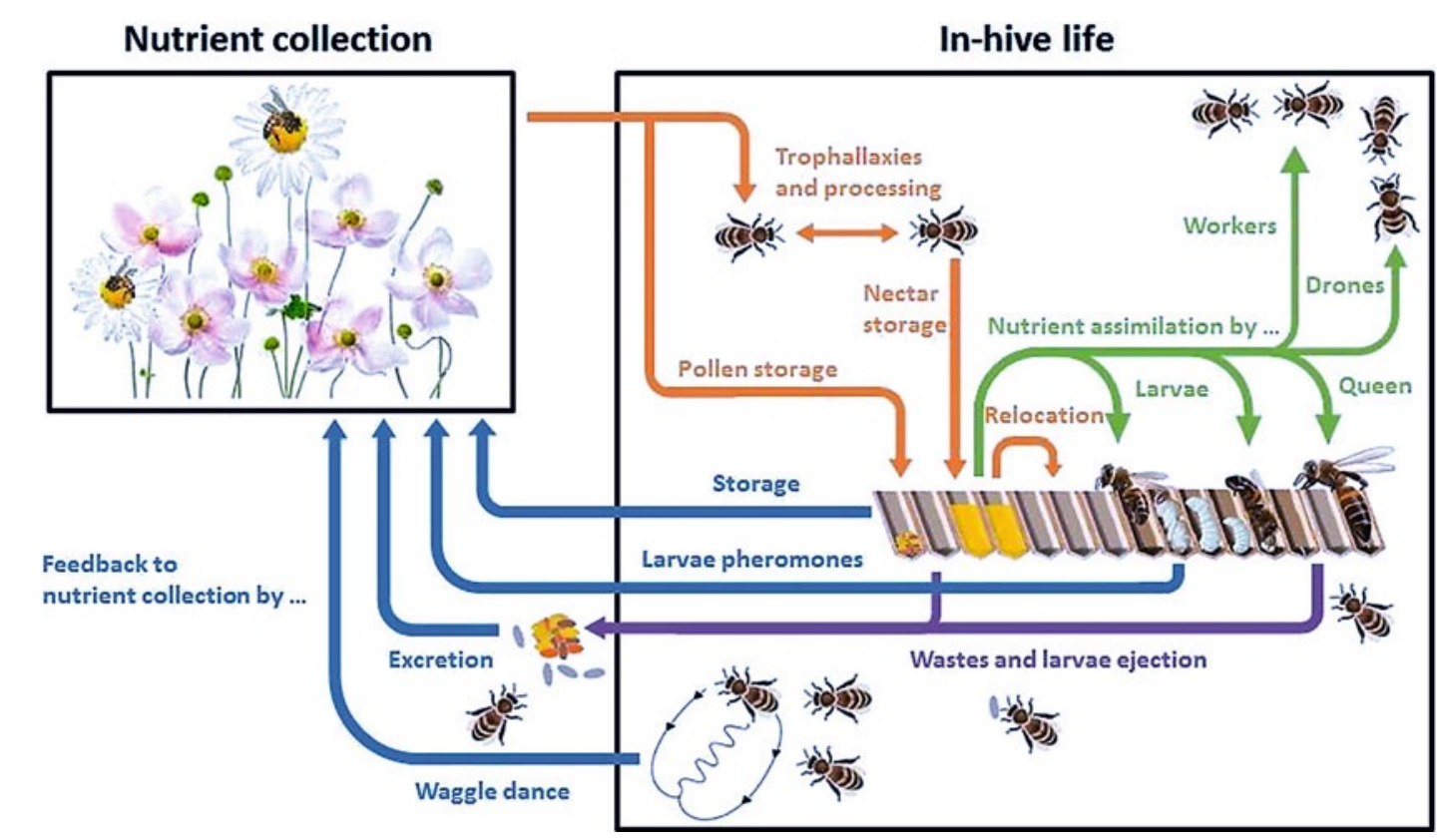

Nutrition in Social Insects, Fig. 1 Nutritional cascades in a honey bee hive, Apis mellifera. Foragers collect nectar and pollen from flowers that they select based on learning and memory. Back at the hive, foragers indicate food location to their nestmates using the waggle dance and share their crop content with the other workers through trophallaxis or unload pollen directly into the cells. Workers ingest and process the food by moving it from cell to cell. Storage gives a direct feedback to foragers to indicate the colony's needs in nectar and/or pollen. Nurses feed the larvae, the queen, the drones, the foragers and the other workers. Larvae release pheromones that indicate the amount and type of food given by the nurses and collected by the foragers that serve as feedback to the foragers. Workers clean the cells and the complete hive

\section{Nutrient Collection}

In most social insects, only a minority of the workers (the foragers) are tasked with feeding the colony. This involves searching for suitable food resources, extracting the food, and trans- porting the required nutrients to the colony. The challenge for the foragers is to balance nutrient collection in order to address the different needs of all colony members. Queens and larvae typically require more proteins and lipids for egg-laying and growth, while workers and males need carbo- hydrates for energy. In species exhibiting food- source recruitment, foragers can share information about the quality and the location of feeding sites relative to the nest, which increases their individual rate of finding the required nutri- ents [6]. Food recruitment often leads to collective decisions whereby groups of foragers exploit one or a few resources among many alternatives. These self-organized behaviors are the result of positive feedback and quorum responses medi- ated by local interactions, such as pheromone trails in ants or the waggle dance in honey bees, often enabling foragers to choose the best available foods in their environment.

\section{Processing and Storage}

In a social insect colony, food intake results from a cascade of interactions in which the food collected by foragers is processed and transmitted to the other workers, the brood and the reproductive individuals, either directly (through liquid food exchanges, or trophallaxis) or indirectly (through food storage) [13]. For instance, honey, the main food source of bees, is made from floral nectar that is first dried by multiple regurgitations and relocations between chambers or comb cells. The final product is 
then elaborated by the action of enzymes added by workers, which considerably increases sugar concentration. Honey can be stored for long periods in dedicated cell combs in the case of honey bees (Apis spp.) and stingless bees (Meliponini), as well as a very few species of social wasps. Some desert ants (Magalophorus spp.) store liquid food derived from sugary plant exudates in the distended crops of honeypot workers. These food reserves reflect the nutritional status of a colony and can inform foragers about specific colony needs. In honey bees, the presence of pollen in nest combs reduces pollen collection by foragers without influencing nectar foraging.

\section{Assimilation and Excretion}

After ingesting food, insects can further regulate their nutrient balance by differentially digesting, retaining, and metabolizing nutrients. At the indi- vidual level, postingestive regulation includes the differential secretion of digestive enzymes to lower the efficiency of digestion of excess of nutrients in the diet, the adjustment of the timing of gut emptying to alter the ratio of nutrients absorbed from the gut, the increase of metabolic rate to burn-off excess ingested nutrients, and the selection of environmental temperatures that favor the utilization of specific nutrients [2]. Excess nutrients or other toxic food components are then eliminated from the body through the Malpighian tubules and the rectum. At the collec- tive level, colonies accumulate wastes or toxic components, such as wax, brood combs, pellets of pollen, or even dead bodies. This waste is removed from the colony by the workers and can also inform the foragers about the nutritional sta- tus of the colony. For instance, ants constrained to a high-protein diet reject the excess of protein in the form of pellets stockpiled in a waste dump outside the nest that signals a need for more car- bohydrates [4]. In bees, unfavorable environmen- tal conditions can lead workers to eject larvae from the nest or even to eat some of them due to lack of protein collection.

\section{Symbioses}

Symbiotic organisms can provide novel meta- bolic capabilities allowing insects to occupy new nutritional niches. About $10 \%$ of all insects utilize diets that are nutritionally so poor or unbalanced that they depend on microorganisms to degrade complex dietary components into components that can be assimilated by the insects. Wood-feed- ing termites are a striking example [10]. In the lower termites, $75 \%$ of total cellulose activity in the gut is mediated by protists. These microorgan- isms engulf fragments of plant materials and fer- ment the cellulose to produce short-chain fatty acids that are absorbed in the hindgut and provide a large proportion of the respiratory substrate used by the insect. Other termite species gain access to cellulose by associating with ectosymbiotic cellu- lolytic fungi that they maintain in their nest and carry with them when founding new colonies. Fungus-gardening ants and termites cultivate a symbiont that composts plant fragments and turns them into digestible food for the insects, especially for the larvae that feed on the fungal mycelium. In attine ants, whose fungal cultivars have conserved their capacity for independent reproduction, foragers collect protein and carbo- hydrates in amounts and ratios that promote the growth of edible fungal somatic tissues while inhibiting the production of nonedible reproduc- tive tissues and nonsymbiotic fungi [11]. 


\section{Differential Feeding and Caste Fate}

In social Hymenoptera, the caste differentiation characteristic of eusociality is partly determined by conditions experienced during the larval life. In honey bees, a newly hatched female larva has the potential to develop into either a sterile worker or a reproductive queen depending on the quality and quantity of the food she receives [9]. If given a diet based primarily on the secretion of the nurse bees' mandibular glands (royal jelly), the larva becomes a queen. If given larger proportions of secretion from the hypopharyngeal glands of the workers, the larva becomes a worker. In this process, larvae are not simply passive recep- tors but also inform workers about their nutri- tional needs by chemicals (brood pheromones) promoting foraging. These pheromones consist of a blend of ten fatty-acid esters, such as the methyl linoleate that stimulates workers to enhance the deposit of royal jelly, or the methyl palmitate that informs about the increase of larvae weight. Division of labor mediated by differential nutrition of the lavae by the adults is also involved in the production of the different worker castes. In ants, larvae fed high-protein diets are more likely to become large workers (major or soldiers) than are larvae fed low-protein diets.
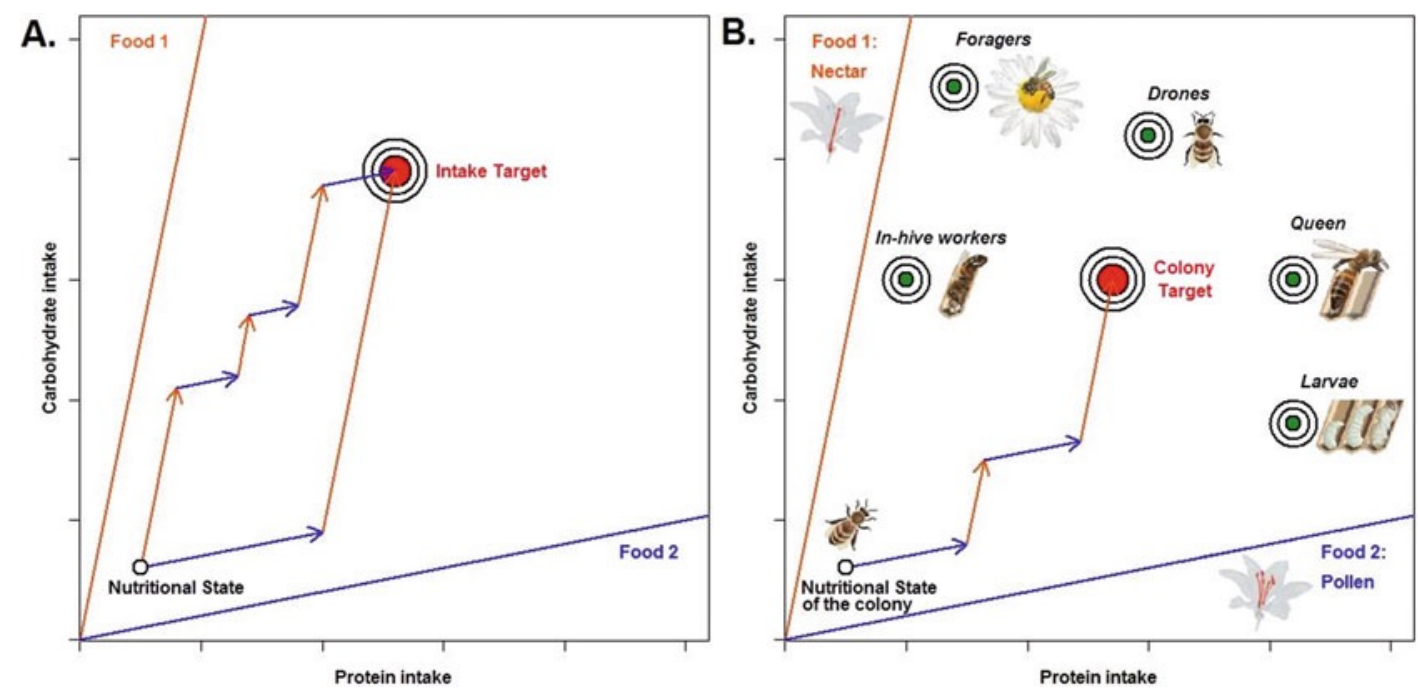

Nutrition in Social Insects, Fig. 2 Principles of nutritional geometry. (a) Example of nutritional geometry model for a hypothetical individual animal. The environ- ment is modeled as a nutrient space defined by two nutrients: carbohydrate and protein. The individual's nutritional state is represented by the small white dot and its intake target (nutritional state optimizing performance trait) by the larger red dot. Nutritional rails (orange and blue lines) represent the ratio of two key nutrients in foods. In this example, the individual can reach its intake target by eating from the two individually imbalanced but collectively complementary foods 1 and 2 (see two examples of sequences of arrows). (b) Hypothetical example of nutri- tional geometry model for a honey bee colony. Foragers, in-hive workers, drones, larvae and the queen have their own intake targets (small green dots, here shown as aver- ages). The challenge for the foragers is to balance their nutrient collection based on nectar and pollen foraging.

\section{Nutrition and Social Evolution}

Many authors have suggested that nutrition is a major driver of insect social evolution, although a unifying theory is still lacking [5]. For Hymenop- tera, it has been proposed that the evolution of societies with obligate reproductive division of labor is derived from an ancestral ground plan that functions to synchronize dietary preferences of females with those nutrients most essential during specific phases of the reproductive cycle (e.g., a preference for protein during oogenesis) [1]. The reproductive ground 
plan hypothesis posits that reproductive controls of a solitary ancestor have been co-opted with nutritional mechanisms during social evolution, facilitating the division of labor among social insect workers. Empirical support for this hypothesis has been found in honey bees, some solitary bees, and wasps, showing that workers with larger ovaries and higher levels of vitellogenin (a yolk precursor protein) are more responsive to sucrose and more likely to be pollen foragers. This relationship involves endocrine systems such as the $\mathrm{JH}$ and ecdysone pathways and is further influenced by genes in nutrition-associated signaling pathways.

\section{Nutritional Geometry: A Unifying Conceptual Approach Across Levels of Organization}

The broader effects of nutrition in mediating inter- actions between the nutritional environment, the physiology and behavior of individual insects, and their consequences on social behavior and ecological interactions, have been explored using nutritional geometry, a graphical approach to study how animals adjust nutrient collection and ingestion to reach a balanced diet [12]. In nutritional geometry, the nutritional state of an insect is represented as a moving point in a multidimensional nutrient space in which each axis represents a key nutrient, typically carbohy- drates and proteins (Fig. 2a). Foods are radials determined by the balance of nutrients they contain. By consuming food, the insect changes its nutritional state along the chosen food rail. In doing so, it can try to reach and maintain an optimal nutritional state (intake target) maxi- mizing one or several fitness traits.

Nutritional geometry is a powerful means to study how nutritional homeostasis is achieved individually and collectively by a social insect colony [7]. In this approach, all colony members are considered to have their own nutritional state and intake target that may vary with age, caste, and activity. The task for foragers is to collect the required nutrients in amounts and ratios that match the colony level intake target, which com- bines the individual targets of all colony members (Fig. 2b). Nutritional geometry models can be used to predict the blends of foods individuals and colonies should acquire and reject in order to acquire mixtures maximizing colony perfor- mance and to empirically test these predictions in experimental designs using artificial diets. In the past 10 years, this approach has led to several major advances in the field of social insect nutri- tion, and the emergence of new reasearch areas such as the effects of nutrition on cognition, col- lective behavior, host-pathogen interactions, and pollination [8].

\section{References}

1. Amdam, G. V., Csondes, A., Fondrk, M. K., \& Page, R. E. (2006). Complex social behavior derived from maternal reproductive traits. Nature, 439, 76-78.

2. Behmer, S. T. (2009). Insect herbivore nutrient regulation. Annual Review of Entomology, 54, 165- 187.

3. Carson, C. A. (2015). Insect diets science and technology (2nd ed.). Boca Raton: CRC Press.

4. Dussutour, A., \& Simpson, S. J. (2009). Communal nutrition in ants. Current Biology, 19, 740-744.

5. Hunt, J. H., \& Nalepa, C. A. (Eds.). (1994). Nourish- ment and evolution in insect societies. Boulder: Westview.

6. Jeanson, R., Dussutour, A., \& Fourcassié, V. (2012). Key factors for the emergence of collective decision in invertebrates. Frontiers in Neuroscience, 6, 121.

7. Lihoreau, M., Buhl, J., Charleston, M. A., Sword, G. A., Raubenheimer, D., \& Simpson, S. J. (2015). Nutri- tional ecology beyond the individual: A conceptual framework for integrating nutrition and social interac- tions. Ecology Letters, 18, 273-286. 
8. Lihoreau, M., Gomez-Moracho, T., Pasquaretta, C., Costa, J. T., \& Buhl, J. (2018). Social nutrition: An emerging field in insect science. Current Opinion in Insect Science, 28, 73-80.

9. Maleszka, R. (2018). Beyond Royalactin and a master inducer explanation of phenotypic plasticity in honey bees. Communications Biology, 1, 8.

10. Nalepa, C. (2015). Origin of termite eusociality: Trophallaxis integrates the social, nutritional, and microbial environments. Ecological Entomology, 40, 323-335.

11. Shik, J. Z., Gomez, E. B., Kooij, P. W., Santos, J. C., Wcislo, W. T., \& Boomsma, J. J. (2016). Nutrition mediates the expression of cultivar-farmer conflict in a fungus-growing ant. Proceedings of the National Academy of Science of the United States of America, 113, 10121-10126.

12. Simpson, S. J., \& Raubenheimer, D. (2012). The nature of nutrition: A unifying framework from animal adaption to human obesity. Princeton: Princeton University Press.

13. Wright, G. A., Nicolson, S. W., \& Shafir, S. (2018). Nutritional physiology and ecology of honey bees. Annual Review of Entomology, 63, 327-344. 